\title{
C-type natriuretic peptide is a Schwann cell-derived factor for development and function of sensory neurons Ichiro Kishimoto*1, Takeshi Tokudome ${ }^{1}$, Hideki Chusho², Kazuwa Nakao ${ }^{2}$ and Kenji Kangawa ${ }^{1}$
}

\author{
Address: ${ }^{1}$ Department of Biochemistry, National Cardiovascular Center Research Institute, Osaka, Japan and ${ }^{2}$ Department of Medicine and \\ Clinical Science, Kyoto University School of Medicine, Kyoto, Japan \\ Email: Ichiro Kishimoto* - kishimot@ri.ncvc.go.jp \\ * Corresponding author
}

from 4th International Conference of cGMP Generators, Effectors and Therapeutic Implications

Regensburg, Germany. 19-21 June 2009

Published: II August 2009

BMC Pharmacology 2009, 9(Suppl I):P33 doi:I0.1186/147I-22I0-9-SI-P33

This abstract is available from: http://www.biomedcentral.com//47I-22/0/9/SI/P33

(C) 2009 Kishimoto et al; licensee BioMed Central Ltd.

\section{Background}

Cyclic GMP (cGMP) is known to play important roles for neuronal development and neurite pathfinding. However, the regulatory mechanism which governs the synthesis of cGMP in the nervous system is not well defined. In the present study, we examined the role of C-type natriuretic peptide (CNP), which increases intracellular cGMP upon binding to its receptor, guanylyl cyclase (GC)-B, in the peripheral nervous system.

\section{Methods and results}

Immunohistochemistry revealed that CNP is demonstrated in Schwann cells, whereas GC-B mRNA is highly expressed in dorsal root ganglion (DRG) neurons. In cultured DRG neurons, GC-B was demonstrated in dendrites of TrkA-positive cells, where it co-exists with cGMPdependent protein kinase I (cGKI), the major intracellular mediator of cGMP actions. Addition of CNP in the culture medium apparently increased the density of fine neurites, which was accompanied by the increase in phosphorylation of vasodilator-stimulated phosphoprotein (VASP), a cGKI substrate. Furthermore, in the mice deficient for CNP gene (CNP-KO), the numbers of TrkA-positive DRG neurons were diminished. Likewise, there were much less cGKI-positive neurons in DRG and cGKI-positive fibers in dorsal spinal cord of CNP-KO than wild type mice. Finally, CNP-KO mice displayed a decreased response to inflammatory pain compared to wild types.

\section{Conclusion}

Taken together, these results suggest that CNP is derived from Schwann cells and plays an important role for the development and function of nociceptve sensory neurons. 